\title{
Pendeteksi Kecelakaan Lalu Lintas Menggunakan Akselerometer dan GPS Location pada Aplikasi Android
}

\author{
Marcellinus Julian Finlando ${ }^{1}$, Kristian Adi Nugraha ${ }^{2}$, Laurentius Kuncoro Probo Saputra ${ }^{3}$ \\ Program Studi Informatika, Universitas Kristen Duta Wacana \\ Imarcellinus.julianeti.ukdw.ac.id \\ 2adinugraha@ti.ukdw.ac.id \\ ${ }^{3}$ kuncorodstaff.ukdw.ac.id
}

\begin{abstract}
Vehicle accident is of course avoided everyone. Vehicle accidents not only cause injuries, but can also lead to death, and cause other damages such as loss of material. At a vehicle accident there is an important role of the people around, the authorities, and even the family to help the accident victims. Being an issue if these people can not be contacted by the victim, because the victim was not able to use the smartphone because in conditions that do not allow such physical injury or even unconsciousness. In addition there are other factors such as people who do not care because they do not know the victims. By utilizing the android smartphone that is used by most people, it can be designed and developed crash detection system in android application. The app uses the accelerometer sensor and GPS Location as a variable at detecting an accident. If the system detects a crash, the system will automatically send a message to all users who have registered applications. The message in the form of the location of the accident victims, so that readers can instantly access your location via Google Map victim of such messages. This application can facilitate people around, relatives or authorities to be able to know the location of a vehicle accident. So if there is a vehicle accident, it is expected that the people who registered in the application can help accident victims and deal with it quickly.
\end{abstract}

Intisari-Kecelakaan kendaraan merupakan hal yang pastinya dihindari semua orang. Kecelakaan kendaraan tidak hanya menyebabkan korban luka-luka, tetapi dapat juga menyebabkan kematian, dan menyebabkan kerugian lain seperti kerugian materi. Dalam kecelakaan kendaraan terdapat peranan penting orang-orang di sekitar, pihak yang berwenang, dan bahkan keluarga untuk menolong korban kecelakaan. Menjadi sebuah permasalahan tersendiri apabila orang-orang tersebut tidak dapat dihubungi oleh korban, dikarenakan korban sudah tidak dapat memegang smartphone karena dalam kondisi yang tidak memungkinkan seperti cidera fisik atau bahkan tidak sadarkan diri. Selain itu terdapat faktor lain seperti orang-orang yang tidak peduli karena tidak tahu ada korban kecelakaan. Dengan memanfaatkan smartphone android yang digunakan oleh sebagian besar masyarakat, maka dapat dirancang dan dibuat sistem deteksi kecelakaan kendaraan pada aplikasi android. Aplikasi tersebut menggunakan sensor akselerometer dan GPS Location sebagai variabelnya dalam mendeteksi kecelakaan. Apabila sistem mendeteksi kecelakaan, maka sistem akan langsung mengirimkan pesan kepada seluruh pengguna aplikasi yang sudah terdaftar. Pesan tersebut berupa lokasi korban kecelakaan, sehingga para pembacanya dapat langsung mengakses lokasi korban via Google Map dari pesan tersebut. Aplikasi ini dapat memudahkan orang-orang di sekitar, kerabat atau pihak yang berwenang untuk dapat mengetahui lokasi kecelakaan kendaraan. Sehingga jika ada kecelakaan kendaraan, maka diharapkan orangorang yang sudah memiliki dan terdaftar pada aplikasi tersebut dapat menolong korban kecelakaan dan menanganinya secara cepat.

Kata Kunci- Kecelakaan kendaraan, Google Maps, Google Speed, Akselerometer, Kecepatan, Android.

\section{Pendahuluan}

Menurut data dari badan pusat statistika Indonesia, jumlah kecelakaan lalu lintas transportasi darat pada tahun 2017 sebanyak 98.400 kasus dengan jumlah korban yang meninggal sebanyak 26.185 orang[1]. Dengan banyaknya jumlah kecelakaan lalu lintas tersebut membuat pihak-pihak yang bersangkutan seperti rumah sakit atau orang-orang terdekat harus bergerak cepat untuk menangani kasus kecelakaan tersebut. Namun, fenomena kurangnya kepedulian terhadap korban kecelakaan semakin marak, hal ini sangat nampak pada masyarakat yang bukannya menolong dan peduli terhadap korban, tetapi justru sibuk menonton kecelakaan tersebut[2]. Maka dari itu perlunya sistem deteksi kecelakaan yang mampu mengirimkan lokasi korban kecelakaan kepada kerabat atau pihak-pihak yang berwenang.

Banyaknya smartphone yang dimiliki membuat informasi dapat beredar dengan cepat, begitu juga informasi mengenai kecelakaan lalu lintas. Populasi android sendiri di seluruh dunia telah mencapai lebih dari 1 miliar, dan penggunanya rata-rata mengecek ponselnya 150 kali dalam shari[3]. Dari informasi tersebut, maka dapat disimpulkan bahwa seharusnya dapat memanfaatkan teknologi smartphone untuk membuat aplikasi deteksi kecelakaan agar orang-orang yang memakai aplikasi tersebut dapat mengetahui lokasi korban berada. Aplikasi yang akan dibuat memanfaatkan teknologi gps location untuk mendapatkan kecepatan kendaraan serta mendapatkan lokasi korban kecelakaan, dan memanfaatkan teknologi sensor akselerometer untuk mendeksi jatuhnya smartphone itu sendiri, setelah itu dihitung probabilitas setiap kemungkinannya berdasarkan data resultan akselerometer dan standar deviasi kecepatan. Riantana mengatakan bahwa sensor akselerometer dapat mencatat data dari pembacaan getaran di lapangan secara realtime [4] dan menampilkan tiga sumbu utama pada grafik, yaitu sumbu $\mathrm{x}$, sumbu $\mathrm{y}$, dan sumbu z.. 
Hamid dalam penelitiannya menerapkan sensor akselerometer pernah digunakan untuk deteksi kecelakaan mobil menggunakan smartphone dan menyimpulkan bahwa untuk menyaring nilai akselerasi dari sensor akselerometer yang disebabkan jatuhnya smartphone dalam mobil maka dapat diartikan sebagai kecelakaan, dalam hal ini masil diperlukan variabel lain agar lebih akurat [5].

Penerapan sensor akselerometer dalam mengoptimalisasi algoritma deteksi jatuh pada orang tua juga sudah sangat akurat, yang menghasilkan sensitivity sebesar 96,3\% oleh Tran [6].

Penelitian yang dilakukan oleh Arkham Zahri Rakhman, mendapatkan metode untuk deteksi jatuh berdasarkan sensor akselerometer didapatkan dengan menghitung nilai resultan dari ketiga sumbu sensor akselerometer, lalu mencari nilai terbesar dan terkecil resultan akselerometer, dan menghitung selisih nilai terbesar dan terkecil dari resultan akselerometer [7].

Sensor akselerometer juga digunakan dalam penelitian untuk deteksi posisi manusia bergerak jatuh berbasis akselerometer oleh Ruminto Subekti dan menghasilkan nilai specivity sebesar $88 \%$, precision sebesar 93\%, dan accuracy sebesar $88 \%$ [8]. Dari penelitian tersebut dapat disimpulkan bahwa sistem yang dibangun dengan sensor akselerometer telah bekerja dengan baik.

Sistem pendeteksi jatuh berbasis sensor gyroscope dan sensor akselerometer yang dibuat oleh Adlian Jefiza menghasilkan akurasi sebesar 95,455\% dan 97,727\% dalam percobaannya dengan cara memasang sensor tersebut ke arduino dan diletakkan pada tas pinggang[9].

Pemanfaatan Google Maps juga pernah dilakukan pada penelitian oleh Kanedi yang menghasilkan sistem informasi geografis yang berdasarkan Google Maps mampu menyampaikan informasi lokasi dengan tepat [10].

Tujuan dari penelitian ini adalah pembuatan aplikasi android untuk mendeteksi kecelakaan lalu lintas dan mengetahui lokasinya sehingga dapat memberitahukan kepada para pengguna aplikasi tersebut, khususnya pada pihak-pihak yang berwenang.

\section{II.LANDASAN TEORI}

Dalam penelitian ini menggunakan sensor akselerometer, dan modul GPS yang sudah ada pada smartphone android, lalu dilakukan perhitungan probabilitas setiap kemungkinannya berdasarkan data dari resultan akselerometer dan standar deviasi kecepatan.

\section{A.Android}

Menurut Nazruddin [11] android adalah sebuah sistem operasi untuk telepon seluler atau smartphone yang berbasis linux. Untuk membangun sebuah aplikasi android menggunakan bahasa pemrograman java.

\section{B.Sensor Akselerometer}

Akselerometer adalah sensor yang digunakan oleh system untuk mendeteksi orientasi atau pergerakan suatu perangkat berdasarkan gerakan ke segala arah menurut Gunawan [12]. Sensor akselerometer memiliki ketiga sumbu yaitu sumbu $x$, sumbu y, dan sumbu $\mathrm{z}$ atau kiri, kanan, atas, bawah, dan datar.

\section{Global Positioning System (GPS)}

GPS (Global Positioning System) merupakan teknologi penting bagi pada sebuah sistem kendaraan dimana teknologi tersebut dapat merekap beberapa data seperti kecepatan, waktu, dan pastinya navigasi [13].

\section{D.Google Maps}

Google maps adalah aplikasi peta online gratis dari layanan google [14]. Fasilitas google map sudah dihadirkan sejak tahun 2005 dan terus berkembang hingga saat ini. Google maps dapat diakses melalui browser web atau perangkat mobile, salah satu contohnya yaitu perangkat android. Fitur-fitur yang tersedia antara lain mendapatkan tampilan peta dunia, mendapatkan arahan yang detail dari suatu lokasi dan dapat mencari lokasi, melacak pergerakan, dan informasi lainnya.

\section{E.Probabilitas}

Probabilitas adalah suatu nilai untuk mengukur tingkat kemungkinan terjadinya peristiwa yang akan terjadi di masa mendatang yang hasilnya masih belum pasti. Peluang dinyatakan antara 0 dan 1 . Menurut Setyawati, Jika suatu percobaan dapat menghasilkan $N$ macam hasil yang berkemungkinan sama dan jika tepat terdapat sebanyak $n$ hasil yang berkaitan dengan kejadian $A$, maka probabilitas kejadian $A$ adalah [15]

$$
\mathrm{P}(\mathrm{A})=\frac{n}{N}
$$

\section{F. Activity Daily Result}

Specivity merupakan seberapa baik kemampuan sistem menganggap tidak jatuh apabila kendaraan dalam kondisi tidak jatuh. Sehingga apabila sistem menganggap jatuh tetapi kendaraan dalam kondisi tidak jatuh maka akan mengurangi specitivity dalam pengujian.

$$
\text { Specivity }=\frac{\text { True Negative }}{\text { True Negative }+ \text { False Negative }}
$$

Berbeda dengan specitivity, sensitivity merupakan seberapa baik kemampuan sistem menganggap jatuh apabila kendaraan benar-benar terjatuh. Jika sistem menganggap tidak jatuh walaupun kendaraan dalam posisi benar-benar terjatuh, maka akan mengurangi sensitivity dalam pengujian.

$$
\text { Sensitivity }=\frac{\text { True Positive }}{\text { True Positive }+ \text { False Negative }}
$$

\section{METODOLOGI PENELITIAN}

Hasil pada penelitian ini nantinya berupa aplikasi android, dimana aplikasi ini bertugas untuk mendeteksi kecelakaan lalu lintas pada pengendaranya dengan menggunakan sensor akselerometer dan gps location serta mampu memberikan notifikasi kepada para pengguna lainnya lokasi dimana kecelakaan berada. Langkah-langkah sistem dalam mendeteksi kecelakaan dijelaskan seperti berikut: 


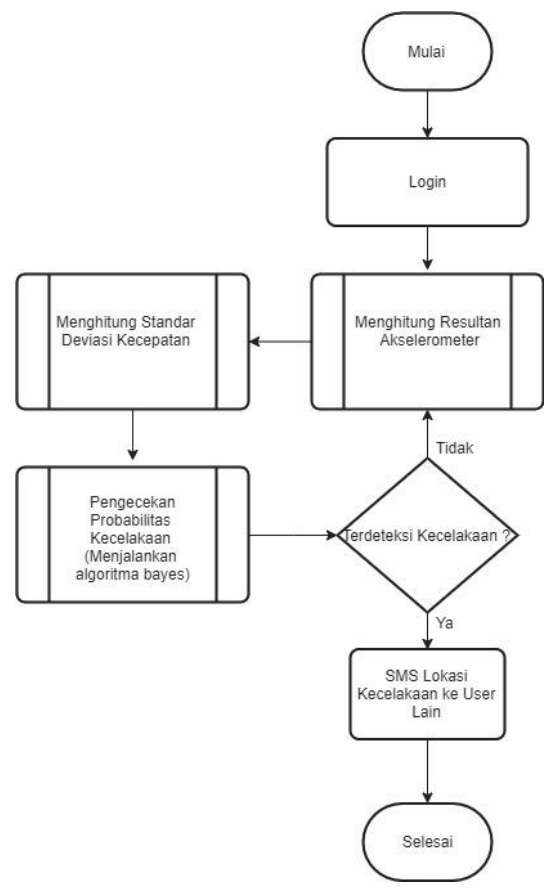

Gambar. 1. Flowchart deteksi kecelakaan secara keselruhan

Gambar 1 ditunjukkan alur kerja sistem secara keseluruhan. Mula-mula, pengguna harus login ke dalam aplikasi agar dapat melanjutkan ke proses selanjutnya. Kemudian, sistem akan menghitung resultan dari ketiga sumbu akselerometer, yaitu sumbu x, sumbu y, dan sumbu z. Selanjutnya sistem juga menghitung standar deviasi dari kecepatan motor dan melakukan pengecekan probabilitas terjadinnya kecelakaan. Perhitungan probabilitas tersebut berdasarkan data yang didapat dari pengambilan data resultan akselerometer ketika jatuh dan tidak jatuh, dan data standar deviasi kecepatan ketika jatuh dan tidak jatuh. Selama aplikasi dijalankan, sistem akan terus-menerus melakukan pengecekan terjadinya kecelakaan. Jika terdeteksi kecelakaan, sistem akan otomatis mengirimkan lokasi korban kecelakaan kepada semua pengguna aplikasi, sehingga para pengguna aplikasi ini, dapat langsung melihat lokasi korban kecelakaan dengan menggunakan google maps.

\section{A.Deteksi Jatuh dengan Sensor Akselerometer}

Terdapat dua variabel untuk mendeteksi jatuh yaitu dengan menggunakan sensor akselerometer untuk menghitung nilai resultan dari ketiga sumbunya, dan dengan menggunakan GPS Speedometer untuk menghitung kecepatan kendaraan. Metode yang digunakan untuk mendeteksi jatuh dengan menggunakan sensor akselerometer yaitu dengan menghitung nilai resultan akselerometer berdasarkan ketiga sumbu, yaitu sumbu x, sumbu $y$, dan sumbu z pada sensor akselerometer. Nilai resultan yang diperoleh dari ketiga sumbu menggunakan persamaan 6 .

$$
A T t=\sqrt{a X t^{2}+a Y t^{2}+a Z t^{2}}
$$

Gambar 2 menunjukkan alur kerja sistem mendeteksi jatuh dengan akselerometer. Pertama-tama sensor akan mendapatkan nilai dari sumbu $x$, sumbu $y$, dan sumbu z, lalu sistem akan menghitung nilai resultan dari ketiga sumbu tersebut. Setelah mendapatkan nilai resultan dari ketiga sumbu, maka selanjutnya dicari nilai yang terbesar dan yang terkecil dari nilai resultannya, terakhir sistem akan menghitung selisih dari nilai yang terbesar dan terkecil. Jika nilai selisihnya besar maka menandakan smartphone dalam kondisi jatuh, namun sebaliknya jika selisihnya kecil maka menandakan smartphone tidak dalam kondisi jatuh.

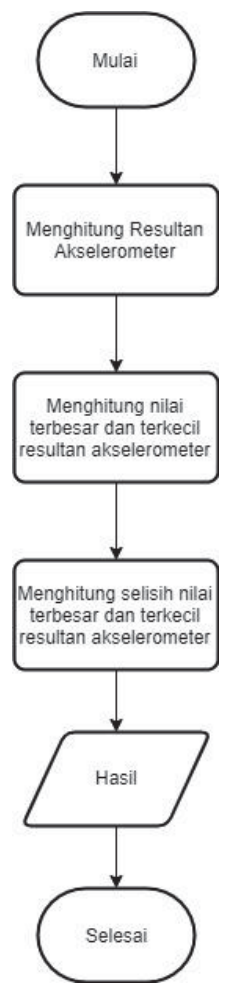

Gambar. 2. Flowchart deteksi jatuh dengan akselerometer.

\section{B.Deteksi Jatuh dengan GPS Speed}

Selain menggunakan sensor akselerometer untuk mendeteksi jatuh, dalam penelitian ini juga akan menggunakan GPS speedometer untuk mendeteksi jatuhnya sepeda motor berdasarkan kecepatan.

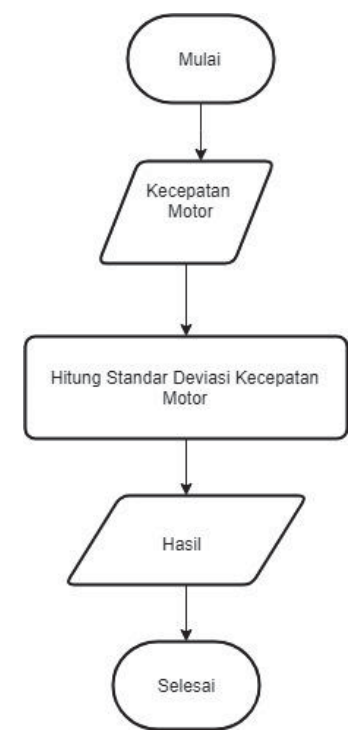

Gambar. 3. Flowchart deteksi jatuh menggunakan GPS speed 
Gambar 3 ditunjukkan alur kerja sistem mendeteksi kendaraan jatuh dengan menggunakan GPS Speedometer. Metode yang digunakan untuk mendeteksi kecelakaan dengan GPS speedometer yaitu dengan mengambil data kecepatan kendaraan, setelah itu melakukan normalisasi data dengan mengambil 10 detik data terakhir untuk memastikan kendaraan jatuh atau tidak. Untuk menentukan kecelakaan atau tidak, menggunakan standar deviasi dari 10 detik data kecepatan terakhir. Maka, semakin tinggi nilai standar deviasi akan mengindikasikan bahwa kendaraan tersebut sedang mengalami kecelakaan, namun apabila nilai standar deviasi kecil maka mengindikasikan kendaraan tersebut tidak mengalami kecelakaan.

\section{C.Perumusan Nilai Probabilitas}

Pengambilan data pada penelitian ini dibagi menjadi dua bagian, yaitu bagian pertama untuk mengambil data percepatan dari sensor akselerometer dan bagian kedua untuk mengambil data kecepatan kendaraan dari GPS speedometer. Data yang diperoleh merupakan keluaran data yang sudah dicatat melalui kode program dengan format microsoft excel agar dapat merepresentasikan dalam bentuk grafik.

Bagian pertama untuk mengambil data percepatan dari sensor akselerometer yang sudah terdapat pada smartphone sebanyak 60 dataset. Data pertama yaitu data dengan kondisi kendaraan jatuh sebanyak 30 kali, lalu data kedua dengan kondisi kendaraan tidak jatuh sebanyak 30 kali. Untuk pengambilan data percepatan, dilakukan simulasi kecelakaan dengan cara memutar dan menggoyangkan smartphone ke segala arah seolah smartphone jatuh. Sedangkan untuk pengambilan data tidak jatuh dengan cara berkendara sambil tidak memutar dan menggoyangkan smartphone.

\section{D.Skenario Pengujian Sistem}

Setelah sistem selesai dibuat, maka akan dilakukan pengujian untuk menguji seberapa akurat sistem dalam mendeteksi kecelakaan saat pengendara mengalami kecelakaan atau dalam mendeteksi tidak kecelakaan saat pengendara dalam kondisi aman atau tidak kecelakaan. Selain itu pengujian sistem juga dilakukan untuk menguji specitivity dan sensitivity sistem seperti pada Tabel 1

TABEL I

TABEl SKenARIo PENGUJian Sistem

\begin{tabular}{|c|c|c|}
\hline No & Skenario & Total \\
\hline 1 & Jalan aspal halus & 60 \\
\hline 2 & Jalan aspal bergelombang & 60 \\
\hline 3 & Jalan aspal dengan beberapa polisi & 60 \\
& tidur & \\
\hline
\end{tabular}

\section{HASIL DAN ANALISIS}

Hasil dari penelitian ini adalah aplikasi deteksi kecelakaan pada platform android yang dibangun dengan menggunakan bahasa pemrograman java. Fitur-fitur yang dimiliki antara lain, pengguna dapat melakukan login untuk masuk ke dalam aplikasi, jika pengguna belum terdaftar, maka pengguna harus melakukan registrasi terlebih dahulu agar dapat menggunakan aplikasi. Selain itu fitur utama pada apliaksi ini yaitu, sistem dapat mendeteksi kecelakaan apabila smartphone sedang berada Bersama pengendaranya. Jika terdeteksi kecelakaan, maka sistem akan memberikan pesan singkat yang berupa lokasi kecelakaan kepada para pengguna lainnya, sehingga para pengguna aplikasi tersebut dapat langsung melihat lokasi korban kecelakaan dengan mengakses langsung link lokasi korban kecelakaan pada pesan singkat yang dikirimkan.

\section{A.Implementasi Pengambilan Data}

Pada penelitian ini, dilakukan pengambilan data training terlebih dahulu untuk membuat perumusan nilai probabilitas.

Pengambilan data dilakukan dengan keadaan jalan aspal yang lurus dan dalam kecepatan kurang lebih $20-40$ $\mathrm{km} /$ jam. Pengambilan data pada penelitian ini dibagi menjadi dua bagian, yaitu bagian pertama untuk mengambil data percepatan dari sensor akselerometer dan bagian kedua untuk mengambil data kecepatan kendaraan dari GPS speedometer. Data yang diperoleh merupakan keluaran data yang sudah dicatat melalui kode program dengan format microsoft excel agar dapat merepresentasikan dalam bentuk grafik. Setelah itu data diolah dengan menggunakan rumus peluang untuk menghitung nilai setiap probabilitasnya.

Untuk implementasi pengambilan setiap data berdasarkan percepatan dan kecepatan kendaraan yaitu :

\section{1) Implementasi Pengambilan Data Percepatan}

Bagian pertama untuk mengambil data percepatan dari sensor akselerometer yang sudah terdapat pada smartphone sebanyak 60 dataset. Data pertama yaitu data dengan kondisi kendaraan jatuh sebanyak 30 kali, lalu data kedua dengan kondisi kendaraan tidak jatuh sebanyak 30 kali. Untuk pengambilan data percepatan, dilakukan simulasi kecelakaan dengan cara memutar dan menggoyangkan smartphone ke segala arah dan melakukan simulasi jatuh. Sedangkan untuk pengambilan data tidak jatuh dengan cara berkendara sambil tidak memutar dan menggoyangkan smartphone. Tabel 2 memperlihatkan salah satu contoh data resultan akselerometer ketika dalam posisi tidak jatuh. Sedangkan Tabel 3 memperlihatkan salah satu contoh data resultan akselerometer ketika dalam posisi jatuh. Data yang diambil meliputi sumbu x, sumbu y, sumbu z pada akselerometer dan nilai resultan dari ketiga sumbu tersebut.

TABEL II

DATA RESULTAN AKSELEROMETER KETIKA DALAM POSISI TIDAK JATUH

\begin{tabular}{|c|c|c|c|}
\hline Acc-x & Acc-y & Acc-z & ATt \\
\hline 0,08 & 1,62 & 9,08 & 9,22 \\
\hline 0,24 & 1,57 & 10,01 & 10,14 \\
\hline 0,69 & 1,60 & 10,76 & 10,90 \\
\hline 0,72 & 1,68 & 11,52 & 11,66 \\
\hline 0,59 & 1,68 & 12,01 & 12,14 \\
\hline 0,52 & 1,55 & 11,83 & 11,95 \\
\hline 0,44 & 1,25 & 11,29 & 11,37 \\
\hline 0,36 & 1,10 & 10,36 & 10,42 \\
\hline 0,32 & 1,30 & 9,16 & 9,25 \\
\hline
\end{tabular}

JUTEI Edisi Volume.4 No.1 April 2020 ISSN 2579-3675, e-ISSN 2579-5538 DOI 10.21460/jutei.2020.41.189 


\begin{tabular}{|c|c|c|c|}
\hline 0,31 & 1,67 & 8,43 & 8,60 \\
\hline 0,20 & 1,86 & 8,35 & 8,56 \\
\hline$-0,06$ & 1,83 & 8,72 & 8,91 \\
\hline$-0,31$ & 1,54 & 9,39 & 9,52 \\
\hline$-0,33$ & 1,35 & 10,20 & 10,30 \\
\hline$-0,23$ & 1,40 & 10,91 & 11,00 \\
\hline$-0,11$ & 1,45 & 11,38 & 11,47 \\
\hline 0,04 & 1,51 & 11,49 & 11,59 \\
\hline 0,26 & 1,48 & 11,27 & 11,37 \\
\hline 0,40 & 1,44 & 10,77 & 10,87 \\
\hline 0,35 & 1,47 & 10,32 & 10,44 \\
\hline
\end{tabular}

TABEL III

DATA RESULTAN AKSELEROMETER KETIKA DALAM POSISI JATUH

\begin{tabular}{|c|c|c|c|}
\hline Acc-x & Acc-y & Acc-z & ATt \\
\hline 1,08 & $-3,50$ & 10,03 & 10,68 \\
\hline 0,64 & $-3,42$ & 7,91 & 8,65 \\
\hline 0,75 & $-2,38$ & 6,46 & 6,93 \\
\hline 0,54 & $-1,48$ & 6,08 & 6,29 \\
\hline 0,30 & $-0,85$ & 6,74 & 6,80 \\
\hline 0,68 & 0,14 & 8,36 & 8,39 \\
\hline 0,73 & 2,44 & 11,57 & 11,84 \\
\hline$-0,70$ & 5,64 & 15,82 & 16,81 \\
\hline$-1,58$ & 4,49 & 15,33 & 16,06 \\
\hline 2,67 & $-0,48$ & 10,97 & 11,30 \\
\hline 4,25 & $-2,07$ & 9,27 & 10,41 \\
\hline 2,82 & $-1,65$ & 10,49 & 10,99 \\
\hline 1,02 & $-0,60$ & 12,18 & 12,24 \\
\hline 0,11 & 1,02 & 13,70 & 13,73 \\
\hline 2,51 & 0,47 & 11,94 & 12,21 \\
\hline 2,16 & 0,74 & 9,43 & 9,70 \\
\hline 1,70 & 1,10 & 9,18 & 9,40 \\
\hline 1,51 & 1,30 & 9,77 & 9,97 \\
\hline 1,27 & 1,04 & 9,72 & 9,86 \\
\hline 0,90 & 1,51 & 13,96 & 14,07 \\
\hline
\end{tabular}

Gambar 4 dan Gambar 5 adalah grafik dari data resultan sensor akselerometer dalam periode waktu 10 detik. Dapat dilihat bahwa terdapat perbedaan antara kedua gambar tersebut, dimana Gambar 4 memperlihatkan perbedaan nilai terbesar dan nilai terkecil resultan akselerometer tidaklah tinggi. Sedangnkan pada Gambar 5 selisih nilai terbesar dan terkecil resultan akselerometer tinggi yang menandakan kondisi smartphone dalam keadaan jatuh.

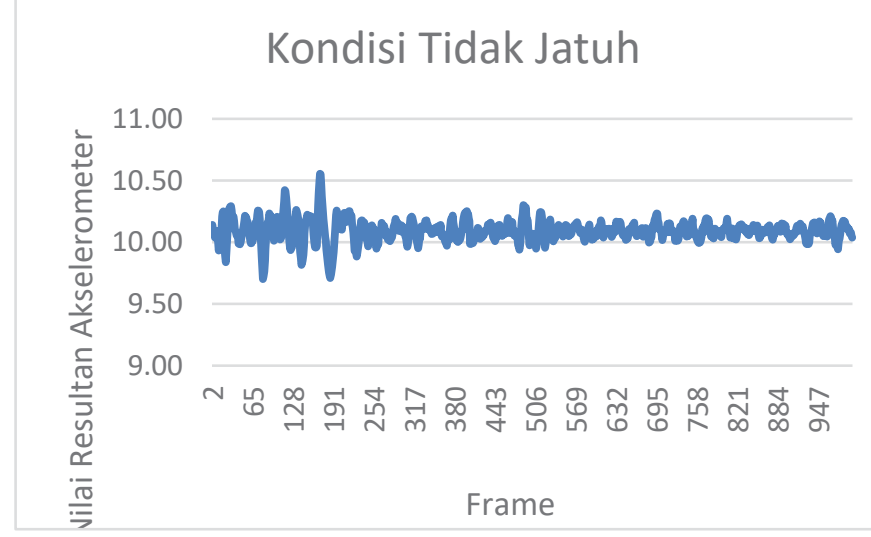

Gambar. 4. Grafik resultan akselerometer ketika tidak dalam kondisi jatuh

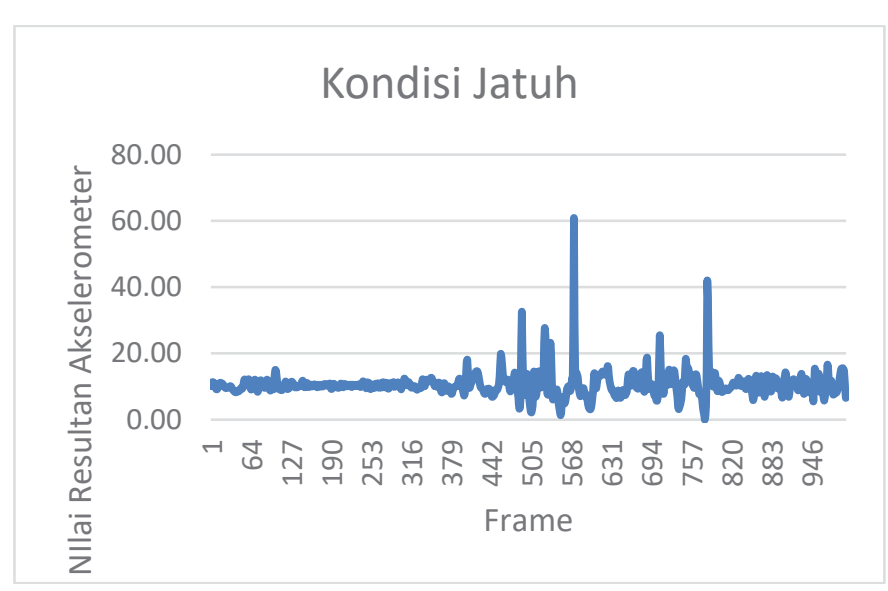

Gambar. 5. Grafik resultan akselerometer ketika dalam kondisi jatuh

2) Implementasi Pengambilan Data Kecepatan

Pada bagian kedua untuk mengambil data kecepatan dari GPS Speedometer sebanyak 60 dataset. Dalam pengambilan data ini menggunakan library dari GPS yang sudah ada pada android studio. Data pertama yaitu data dengan kondisi kecelakaan sebanyak 30 kali dan data kedua dengan kondisi kendaraan tidak mengalami kecelakaan sebanyak 30 kali. Untuk pengambilan data kecepatan, dilakukan simulasi kecelakaan dengan cara mengerem kendaraan secara mendadak lalu motor dimiringkan kea rah kanan dan kiri. Sedangkan untuk pengambilan data tidak kecelakaan dengan cara berkendara dengan kecepatan konstan. Tabel 4 memperlihatkan salah satu contoh data kecepatan kendaraan ketika konstan dan berubah-ubah. Pada kecepatan berubahubah dapat menandakan bahwa kendaraan tersebut sedang mengalami kecelakaan atau dalam kondisi jatuh.

TABEL IV

CONTOH DATA KECEPATAN

\begin{tabular}{|c|c|c|}
\hline No & $\begin{array}{c}\text { Kecepatan } \\
\text { Konstan }\end{array}$ & $\begin{array}{c}\text { Kecepatan } \\
\text { Berubah- } \\
\text { Ubah }\end{array}$ \\
\hline 1 & 20 & 12 \\
\hline 2 & 22 & 16 \\
\hline 3 & 22 & 17 \\
\hline 4 & 22 & 20 \\
\hline 5 & 23 & 20 \\
\hline 6 & 23 & 23 \\
\hline 7 & 23 & 24 \\
\hline 8 & 23 & 25 \\
\hline 9 & 24 & 26 \\
\hline 10 & 24 & 26 \\
\hline 11 & 24 & 25 \\
\hline 12 & 25 & 21 \\
\hline 13 & 25 & 21 \\
\hline
\end{tabular}




\begin{tabular}{|c|c|c|}
\hline 14 & 24 & 14 \\
\hline 15 & 23 & 9 \\
\hline 16 & 22 & 12 \\
\hline 17 & 22 & 13 \\
\hline 18 & 21 & 12 \\
\hline 19 & 22 & 12 \\
\hline 20 & 22 & 12 \\
\hline
\end{tabular}

tabel tersebut diperoleh dari percobaan jatuh dan tidak jatuh yang dilakukan sebanyak 60 kali untuk mencari data resultan akselerometer.

TABEL V

HASIL PERHITUNGAN SELISIH TERBESAR DAN TERKECIL NILAI RESULTAN AKSELEROMETER

Gambar 6 merupakan grafik dari kecepatan GPS Speedometer, dapat dilihat bahwa nilai kecepatan kendaraan memiliki varian yang sedikit dan menandakan bahwa tidak terjadi kecelakaan. Sedangkan Gambar 7 merupakan grafik ketika kendaraan mengalami kecelakaan, dapat dilihat bahwa grafik tersebut memiliki varian data yang banyak.

\section{Kecepatan Konstan}

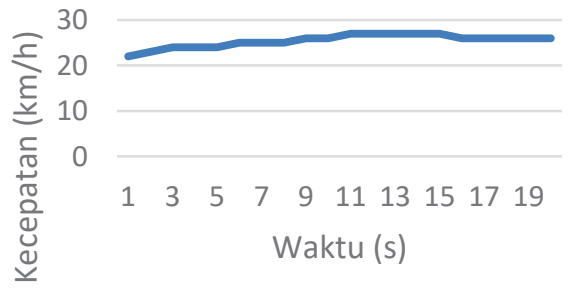

Gambar. 6. Grafik kecepatan konstan.

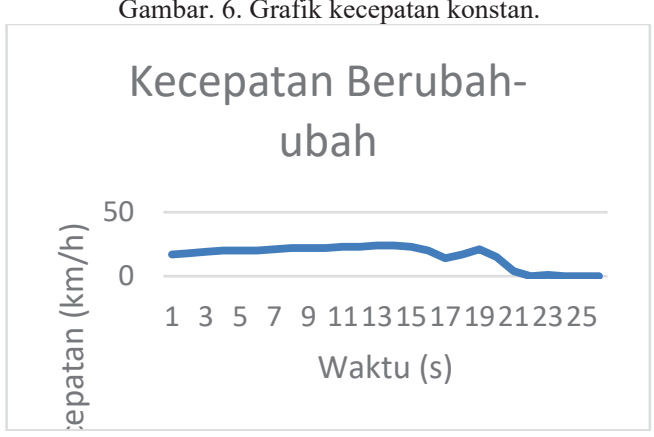

Gambar. 7. Grafik kecepatan berubah-ubah (Jatuh).

\section{B.Implementasi Perumusan Nilai Probabilitas}

Terdapat dua keputusan dan enam rules yang didapatkan pada penelitian ini. Dua keputusan yaitu probabilitas terjadi kecelakaan tanpa memandang evidence apapun dan probabilitas tidak terjadi kecelakaan tanpa memandang evidence apapun. Dua keputusan tersebut sama-sama bernilai 0,5 karena saat di jalan seorang pengendara memiliki probabilitas terjadi kecelakaan sebanyak 50\%. Selain itu, setelah didapatkan data selisih nilai terbesar dan terkecil dari resultan akselerometer, dan standar deviasi kecepatan kendaraan, maka dapat dicari nilai setiap probabilitasnya.

\section{1) Perumusan Nilai Probabilitas dari Resultan Akselerometer}

Tabel 5 memperlihatkan hasil perhitungan dari selisih terbesar dan terkecil nilai resultan akselerometer. Data dari

\begin{tabular}{|c|c|c|}
\hline No & $\begin{array}{c}\text { Selisih ATt Dalam } \\
\text { Kondisi Tidak Jatuh }\end{array}$ & $\begin{array}{l}\text { Selisih ATt Dalam } \\
\text { Kondisi Jatuh }\end{array}$ \\
\hline 1 & 8,46 & 24,61 \\
\hline 2 & 18,19 & 25,02 \\
\hline 3 & 10,13 & 28,08 \\
\hline 4 & 22,86 & 27,70 \\
\hline 5 & 18,22 & 21,89 \\
\hline 6 & 22,49 & 24,72 \\
\hline 7 & 9,62 & 31,37 \\
\hline 8 & 18,59 & 27,73 \\
\hline 9 & 10,84 & 59,70 \\
\hline 10 & 21,74 & 25,21 \\
\hline 11 & 11,54 & 23,68 \\
\hline 12 & 16,68 & 29,85 \\
\hline 13 & 15,15 & 25,36 \\
\hline 14 & 18,22 & 31,33 \\
\hline 15 & 10,83 & 27,04 \\
\hline 16 & 17,86 & 36,53 \\
\hline 17 & 11,77 & 24,90 \\
\hline 18 & 20,74 & 25,32 \\
\hline 19 & 12,30 & 29,65 \\
\hline 20 & 26,07 & 44,20 \\
\hline 21 & 15,60 & 34,73 \\
\hline 22 & 15,68 & 23,25 \\
\hline 23 & 13,11 & 33,53 \\
\hline 24 & 3,62 & 27,38 \\
\hline 25 & 2,62 & 32,70 \\
\hline 26 & 2,49 & 29,36 \\
\hline 27 & 1,97 & 42,81 \\
\hline 28 & 4,57 & 46,41 \\
\hline 29 & 2,56 & 33,99 \\
\hline 30 & 1,73 & 40,16 \\
\hline
\end{tabular}

Setelah mendapatkan data selisih terbesar dan terkecil dari resultan akselerometer dari kedua percobaan yaitu ketika jatuh dan tidak jatuh, maka dapat dihitung nilai probabilitas setiap kemungkinannya untuk memberikan nilai pada masing-masing rules.

Didapatkan irisan dari kedua data tabel tersebut, yaitu dari nilai 21,89 sampai 26,07. Irisan ini didapat dari nilai batas bawah pada data jatuh yaitu 21,89 dan nilai batas atas pada data tidak jatuh yaitu 26,07. Setelah itu, didapatkan nilai probabilitasnya yaitu:

Probabilitas terjadi kecelakaan jika selisih nilai terbesar dan terkecil resultan dari 21,89 sampai 26,07 dengan sebagai berikut:

$$
\mathrm{P}(\mathrm{A})=\frac{n}{N}=\frac{10}{30}=0,33
$$

Probabilitas tidak terjadi kecelakaan jika selisih nilai terbesar dan terkecil resultan dari 21,898 sampai 26,071 sebagai berikut:

$$
\mathrm{P}(\mathrm{A})=\frac{n}{N}=\frac{3}{30}=0,10
$$


Probabilitas terjadi kecelakaan jika selisih nilai terbesar dan terkecil resultan lebih dari 26,071 sebagai berikut:

$$
\mathrm{P}(\mathrm{A})=\frac{n}{N}=\frac{20}{30}=0,66
$$

Sehingga untuk probabilitas tidak terjadi kecelakaan jika selisih nilai terbesar dan terkecil resultan lebih dari 26,071 yaitu 0,34

Probabilitas tidak terjadi kecelakaan jika selisih nilai terbesar dan terkecil resultan kurang dari 21,898 sebagai berikut:

$$
\mathrm{P}(\mathrm{A})=\frac{n}{N}=\frac{27}{30}=0,90
$$

Sehingga untuk probabilitas terjadi kecelakaan jika selisih nilai terbesar dan terkecil resultan kurang dari 21,898 yaitu 0,10 .

\section{2) Perumusan Nilai Probabilitas dari Kecepatan Kendaraan}

Tabel 6 memperlihatkan hasil perhitungan dari total 30 standar deviasi kecepatan yang digabungkan menjadi satu tabel.

TABEL VI

\begin{tabular}{|c|c|c|}
\hline No & $\begin{array}{c}\text { Selisih ATt Dalam } \\
\text { Kondisi Tidak Jatuh }\end{array}$ & $\begin{array}{l}\text { Selisih ATt Dalam } \\
\text { Kondisi Jatuh }\end{array}$ \\
\hline 1 & 0,87 & 11,09 \\
\hline 2 & 0,69 & 3,97 \\
\hline 3 & 0,91 & 5,22 \\
\hline 4 & 0,69 & 10,40 \\
\hline 5 & 1,05 & 8,49 \\
\hline 6 & 0,52 & 5,95 \\
\hline 7 & 3,10 & 6,63 \\
\hline 8 & 1,66 & 6,53 \\
\hline 9 & 3,74 & 9,02 \\
\hline 10 & 2,00 & 9,22 \\
\hline 11 & 0,42 & 5,77 \\
\hline 12 & 1,59 & 2,75 \\
\hline 13 & 1,64 & 3,81 \\
\hline 14 & 2,67 & 5,88 \\
\hline 15 & 1,50 & 9,43 \\
\hline 16 & 0,48 & 4,39 \\
\hline 17 & 0,52 & 10,18 \\
\hline 18 & 2,86 & 7,64 \\
\hline 19 & 1,22 & 10,79 \\
\hline 20 & 1,56 & 5,78 \\
\hline 21 & 0,42 & 6,94 \\
\hline 22 & 0,78 & 6,86 \\
\hline 23 & 0,69 & 3,86 \\
\hline 24 & 0,87 & 3,92 \\
\hline 25 & 0,63 & 5,09 \\
\hline 26 & 1,26 & 11,95 \\
\hline 27 & 0,94 & 8,89 \\
\hline 28 & 0,63 & 8,55 \\
\hline 29 & 0,94 & 11,69 \\
\hline 30 & 1,15 & 8,17 \\
\hline
\end{tabular}

HASIL STANDAR DEVIASI KECEPATAN
Setelah mendapatkan data standar deviasi kecepatan kendaraan dari kedua percobaan yaitu ketika jatuh dan tidak jatuh, maka selanjutnya dapat dihitung probabilitas setiap kemungkinannya.

Didapatkan irisan dari kedua data tabel tersebut, yaitu dari nilai 2,75 sampai 3,74 . Irisan ini didapat dari nilai batas bawah pada data kecepatan kendaraan ketika kecepatan berubah-ubah/jatuh yaitu 2,75 dan nilai batas atas pada data kecepatan kendaraan dalam keadaan kecepatan konstan atau tidak jatuh yaitu 3,74. Setelah itu, didapatkan nilai probabilitasnya yaitu:

Probabilitas terjadi kecelakaan jika standar deviasi kecepatan dari 2,75 sampai 3,74 dengan sebagai berikut:

$$
\mathrm{P}(\mathrm{A})=\frac{n}{N}=\frac{1}{30}=0,03
$$

Probabilitas tidak terjadi kecelakaan jika standar deviasi kecepatan dari 2,75 sampai 3,74 dengan sebagai berikut:

$$
\mathrm{P}(\mathrm{A})=\frac{n}{N}=\frac{3}{30}=0,10
$$

Probabilitas terjadi kecelakaan jika standar deviasi kecepatan lebih dari 3,74 dengan sebagai berikut :

$$
\mathrm{P}(\mathrm{A})=\frac{n}{N}=\frac{29}{30}=0,96
$$

Sehingga untuk probabilitas tidak terjadi kecelakaan jika standar deviasi kecepatan lebih dari 3,74 yaitu 0,04.

Probabilitas tidak terjadi kecelakaan jika standar deviasi kecepatan kurang dari 2,75 dengan sebagai berikut :

$$
\mathrm{P}(\mathrm{A})=\frac{n}{N}=\frac{27}{30}=0,90
$$

Sehingga untuk probabilitas terjadi kecelakaan jika standar deviasi kecepatan kurang dari 2,75 yaitu 0,10 .

\section{3) Perhitungan Probabilitas Kecelakaan}

Setelah mendapatkan nilai dari semua kemungkinan, maka didapatkan enam rules untuk mendeteksi kecelakaan berdasarkan data dari resultan akselerometer dan standar deviasi kecepatan yang dijelaskan pada Tabel 7.

TABEL VII

ENAM RULES

\begin{tabular}{|l|ll|}
\hline No & \multicolumn{1}{|c|}{ Rules } \\
\hline 1 & \multicolumn{1}{|c|}{ Standar deviasi kecepatan dari 2,75 sampai 3,74 } \\
\hline 2 & Standar deviasi kecepatan lebih dari 3,74 \\
\hline 3 & Standar deviasi kecepatan kurang dari 2,75 \\
\hline 4 & $\begin{array}{l}\text { Selisih nilai terbesar dan terkecil resultan } \\
\text { akselerometer dari 21,89 sampai 26,07 }\end{array}$ \\
\hline 5 & $\begin{array}{l}\text { Selisih nilai terbesar dan terkecil resultan } \\
\text { akselerometer lebih dari 26,07 }\end{array}$ \\
\hline 6 & $\begin{array}{l}\text { Selisih nilai terbesar dan terkecil resultan } \\
\text { akselerometer kurang dari 21,89 }\end{array}$ \\
\hline
\end{tabular}


Berdasarkan keenam rules dan nilai hasil dari perhitungan probabilitas diatas, maka dapat dibuat tabel rules serta nilai probabilitasnya pada Tabel 8 .

TABEL VIII

TABEL RULES DAN NILAI PEMBOBOTAN

\begin{tabular}{|c|c|c|c|}
\hline No & Kode & Pernyataan & Nilai \\
\hline 1 & $\mathrm{P}(\mathrm{H} 1)$ & $\begin{array}{l}\text { Probabilitas terjadi } \\
\text { kecelakaan }\end{array}$ & 0,50 \\
\hline 2 & $\mathrm{P}(\mathrm{H} 2)$ & $\begin{array}{l}\text { Probabilitas tidak terjadi } \\
\text { kecelakaan }\end{array}$ & 0,50 \\
\hline 3 & $\mathrm{P}(\mathrm{E} 1 \mid \mathrm{H} 1)$ & $\begin{array}{l}\text { Probabilitas } \\
\text { kecelakaan jika standar } \\
\text { deviasi kecepatan dari 2,75 } \\
\text { sampai 3,74 }\end{array}$ & 0,03 \\
\hline 4 & $\mathrm{P}(\mathrm{E} 2 \mid \mathrm{H} 1)$ & $\begin{array}{l}\text { Probabilitas terjadi } \\
\text { kecelakaan jika standar } \\
\text { deviasi kecepatan lebih dari } \\
3,74\end{array}$ & 0,96 \\
\hline 5 & $\mathrm{P}(\mathrm{E} 3 \mid \mathrm{H} 1)$ & $\begin{array}{ll}\text { Probabilitas } & \text { terjadi } \\
\text { kecelakaan jika } & \text { standar } \\
\text { deviasi kecepatan } & \text { kurang } \\
\text { dari 2,75 } & \end{array}$ & 0,10 \\
\hline 6 & $\mathrm{P}(\mathrm{E} 4 \mid \mathrm{H} 1)$ & $\begin{array}{l}\text { Probabilitas terjadi } \\
\text { kecelakaan jika selisih nilai } \\
\text { terbesar dan nilai terkecil } \\
\text { resultan akselerometer dari } \\
21,89 \text { sampai 26,07 }\end{array}$ & 0,33 \\
\hline 7 & $\mathrm{P}(\mathrm{E} 5 \mid \mathrm{H} 1)$ & $\begin{array}{l}\text { Probabilitas terjadi } \\
\text { kecelakaan jika selisih nilai } \\
\text { terbesar dan terkecil } \\
\text { resultan akselerometer } \\
\text { lebih dari 26,07 }\end{array}$ & 0,66 \\
\hline 8 & $\mathrm{P}(\mathrm{E} 6 \mid \mathrm{H} 1)$ & $\begin{array}{l}\text { Probabilitas terjadi } \\
\text { kecelakaan jika selisih nilai } \\
\text { terbesar dan terkecil } \\
\text { resultan akselerometer } \\
\text { kurang dari 21,89 }\end{array}$ & 0,10 \\
\hline 9 & $\mathrm{P}(\mathrm{E} 1 \mathrm{H} 2)$ & $\begin{array}{lll}\text { Probabilitas } & \text { tidak } & \text { terjadi } \\
\text { kecelakaan } & \text { jika } & \text { standar }\end{array}$ & 0,10 \\
\hline
\end{tabular}

\begin{tabular}{|c|c|c|c|}
\hline & & $\begin{array}{l}\text { deviasi kecepatan dari } 2,75 \\
\text { sampai } 3,74\end{array}$ & \\
\hline 10 & $\mathrm{P}(\mathrm{E} 2 \mid \mathrm{H} 2)$ & $\begin{array}{l}\text { Probabilitas tidak terjadi } \\
\text { kecelakaan jika standar } \\
\text { deviasi kecepatan lebih dari } \\
3,74\end{array}$ & 0,04 \\
\hline 11 & $\mathrm{P}(\mathrm{E} 3 \mid \mathrm{H} 2)$ & $\begin{array}{l}\text { Probabilitas tidak terjadi } \\
\text { kecelakaan jika standar } \\
\text { deviasi kecepatan } \\
\text { dari } 2,75\end{array}$ & 0,90 \\
\hline 12 & $\mathrm{P}(\mathrm{E} 4 \mid \mathrm{H} 2)$ & $\begin{array}{l}\text { Probabilitas tidak terjadi } \\
\text { kecelakaan jika selisih nilai } \\
\text { terbesar dan nilai terkecil } \\
\text { resultan akselerometer dari } \\
21,89 \text { sampai } 26,07\end{array}$ & 0,10 \\
\hline 13 & $\mathrm{P}(\mathrm{E} 5 \mid \mathrm{H} 2)$ & $\begin{array}{l}\text { Probabilitas tidak terjadi } \\
\text { kecelakaan jika selisih nilai } \\
\text { terbesar dan terkecil } \\
\text { resultan akselerometer } \\
\text { lebih dari 26,07 }\end{array}$ & 0,34 \\
\hline 14 & $\mathrm{P}(\mathrm{E} 6 \mid \mathrm{H} 2)$ & $\begin{array}{l}\text { Probabilitas tidak terjadi } \\
\text { kecelakaan jika selisih nilai } \\
\text { terbesar dan terkecil } \\
\text { resultan akselerometer } \\
\text { kurang dari 21,89 }\end{array}$ & 0,90 \\
\hline
\end{tabular}

\section{C.Aplikasi Deteksi Kecelakaan}

Tampilan pertama dalam aplikasi ini yaitu activity login. Pengguna akan tertuju pada activity login saat pertama kali menjalankan aplikasi ini agar dapat masuk activity berikutnya untuk deteksi kecelakaan. Dapat dilihat pada gambar 8 pengguna harus memasukan email dan kata sandi agar dapat masuk activity utama untuk deteksi kecelakaan.

Jika pengguna belum terdaftar dalam aplikasi tersebut, pengguna harus mendaftar terlebih dahulu melalui activity registrasi. Gambar 9 menunjukkan activity registrasi. Pada activity tersebut, pengguna harus memasukkan email, nama, nomor telepon, dan kata sandi. Nama digunakan sebagai informasi dari nama korban kecelakaan kepada pengguna lainnya, sehingga pengguna lainnya dapat mengetahui siapa yang mengalami kecelakaan. nomor telepon berguna untuk menerima pesan dari smartphone korban kecelakaan, sedangkan email dan kata sandi berguna untuk masuk ke dalam aplikasi. 


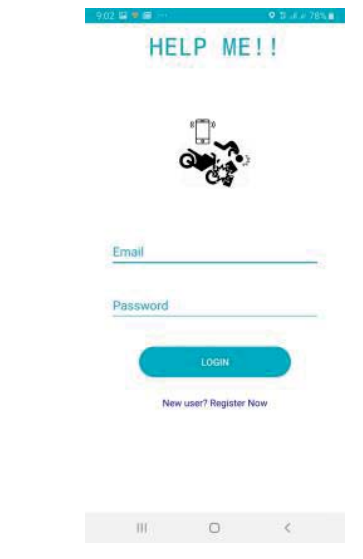

Gambar. 8. Activity login Aplikasi.

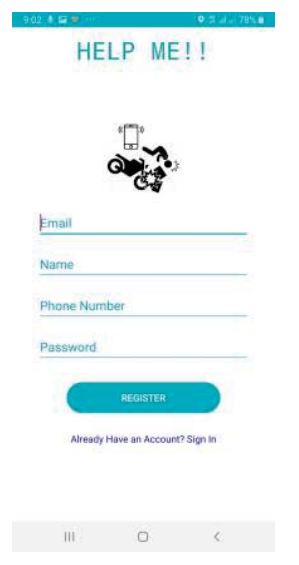

Gambar. 9. Activity register Aplikasi.

Jika pengguna sudah terdaftar dalam aplikasi dan sudah login, maka selanjutnya pengguna masuk ke activity utama untuk deteksi kecelakaan. Aplikasi ini tidak banyak memberikan fitur-fitur dan informasi, karena aplikasi ini berjalan di background dalam smartphone penggunanya tanpa intervensi dari penggunanya. Aplikasi ini akan otomatis berjalan setelah penggunanya masuk, jika pengguna sudah masuk dan tidak logout, maka aplikasi akan otomatis berjalan tanpa harus login terlebih dahulu, sehingga jika aplikasi dijalankan, sistem akan selalu mentedeksi kecelakaan setiap saat. Gambar 10 menunjukkan tampilan aplikasi setelah pengguna login ke dalam aplikasi.

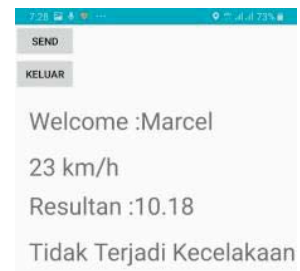

Gambar. 10. Activity utama pada aplikasi.
Saat aplikasi sedang berjalan, jika terdeteksi kecelakaan maka sistem akan langsung memberikan notifikasi pesan yang berisi lokasi kecelakaan korban kepada semua penggunanya. Pengguna dapat langsung membuka pesan dan mengakses langsung link dari lokasi korban kecelakaan seperti pada gambar 11 .

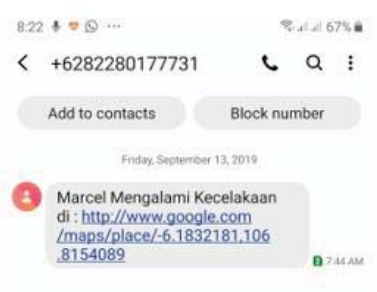

Gambar. 11. Pesan notifikasi korban kecelakaan.

\section{D.Pengujian Aplikasi}

Dalam pengujian ini, dilakukan sebanyak 180 kali pengujian, dengan melakukan 90 kali ketika kendaraan jatuh meliputi 30 kali pengujian pada jalan aspal rata, 30 kali pengujian pada jalan aspal bergelombang, dan 30 kali pengujian pada jalan aspal dengan beberapa polisi tidur, dan dengan 90 kali ketika kendaraan tidak jatuh meliputi 30 kali pengujian pada jalan aspal rata, 30 kali pengujian pada jalan aspal bergelombang, dan 30 kali pengujian pada jalan aspal dengan beberapa polisi tidur. Pengujian dilakukan pada tiga kondisi jalanan yang berbeda. Pertama pada jalan aspal yang rata tanpa gundukan, kedua pada jalan yang bergelombang, dan yang terakhir pada jalan aspal dengan beberapa polisi tidur atau gundukan. Gambar 12 memperlihatkan pengujian aplikasi pada keadaan jatuh dengan menggoyangkan dan memutar smartphone.

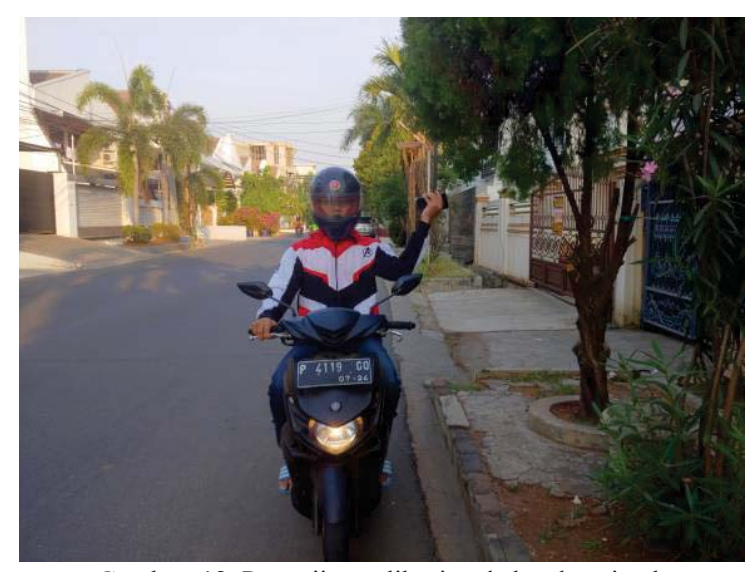

Gambar. 12. Pengujian aplikasi pada keadaan jatuh

Untuk simulasi pengujian jatuh, pada penelitian ini penguji tidak benar-benar jatuh dari kendaraan, dikarenakan dapat membahayakan penguji. Maka dari itu dilakukan simulasi jatuh yang berupa memutar, membalikkan, dan menggoyangkan smartphone sehingga mirip dengan keadaan jatuh.

Tabel 9 dan Tabel 10 merupakan hasil dari pengujian aplikasi. Tabel 11 hasil dari pengujian aplikasi ketika jatuh, sedangkan Tabel 10 hasil dari pengujian aplikasi ketika tidak jatuh. 
TABEL IX

HASIL PENGUJIAN SISTEM DAN AKURASI APLIKASI DALAM KEADAAN JATUH

\begin{tabular}{|c|l|c|c|c|c|}
\hline No & Skenario & $\begin{array}{c}\text { Tot } \\
\text { al }\end{array}$ & $\begin{array}{c}\text { Sistem } \\
\text { mengang } \\
\text { gap jatuh }\end{array}$ & $\begin{array}{c}\text { Sistem } \\
\text { mengang } \\
\text { gap tidak } \\
\text { jatuh }\end{array}$ & $\begin{array}{c}\text { Akur } \\
\text { asi }\end{array}$ \\
\hline 1 & $\begin{array}{l}\text { Jalan } \\
\text { aspal } \\
\text { rata }\end{array}$ & 30 & 28 & 2 & $93 \%$ \\
\hline 2 & $\begin{array}{l}\text { Jalan } \\
\text { aspal } \\
\text { bergelo } \\
\text { mbang }\end{array}$ & 30 & 29 & 1 & $96 \%$ \\
\hline 3 & $\begin{array}{l}\text { Jalan } \\
\text { aspal } \\
\text { dengan } \\
\text { polisi } \\
\text { tidur }\end{array}$ & 30 & 30 & 0 & $100 \%$ \\
\hline
\end{tabular}

TABEL X

HASIL PENGUJIAN SISTEM DAN AKURASI APLIKASI DALAM KEADAAN TIDAK JATUH

\begin{tabular}{|c|l|c|c|c|c|}
\hline No & Skenario & $\begin{array}{c}\text { Tot } \\
\text { al }\end{array}$ & $\begin{array}{c}\text { Sistem } \\
\text { mengang } \\
\text { gap jatuh }\end{array}$ & $\begin{array}{c}\text { Sistem } \\
\text { mengang } \\
\text { gap tidak } \\
\text { jatuh }\end{array}$ & $\begin{array}{c}\text { Akur } \\
\text { asi }\end{array}$ \\
\hline 1 & $\begin{array}{l}\text { Jalan } \\
\text { aspal } \\
\text { rata }\end{array}$ & 30 & 4 & 26 & $86 \%$ \\
\hline 2 & $\begin{array}{l}\text { Jalan } \\
\text { aspal } \\
\text { bergelo } \\
\text { mbang }\end{array}$ & 30 & 3 & 27 & $90 \%$ \\
\hline 3 & $\begin{array}{l}\text { Jalan } \\
\text { aspal } \\
\text { dengan } \\
\text { polisi } \\
\text { tidur }\end{array}$ & 30 & 10 & 20 & $66 \%$ \\
\hline
\end{tabular}

Dari hasil pengujian sistem ketika jatuh, sistem menganggap jatuh pada kondisi jalan aspal rata sebanyak 28 kali dengan tingkat akurasi 93\%, lalu pada kondisi jalan aspal bergelombang sebanyak 29 kali dengan tingkat akurasi 96\%, dan pada kondisi jalan aspal dengan beberapa polisi tidur sebanyak 30 kali dengan tingkat akurasi 100\%. Maka dari itu dapat disimpulkan bahwa dalam kondisi jatuh, sistem akan sangat akurat pada kondisi jalan aspal yang terdapat beberapa polisi tidur karena pada kondisi jalan tersebut tidaklah rata, sehingga nilai selisih terbesar dan terkecil resultan akselerometer tinggi.

Dari hasil pengujian sistem ketika tidak jatuh, sistem menganggap tidak jatuh pada kondisi jalan aspal rata sebanyak 26 kali dengan tingkat akurasi $86 \%$, lalu pada kondisi jalan aspal bergelombang sebanyak 27 kali dengan tingkat akurasi $90 \%$, dan yang terkahir pada kondisi jalan aspal dengan beberapa polisi tidur sebanyak 20 kali dengan tingkat akurasi 66\%. Maka dari itu dapat disimpulkan bahwa dalam kondisi tidak jatuh, sistem akan sangat akurat pada kondisi jalan aspal yang rata, hal ini dikarenakan pada jalan aspal rata tidak ada gundukan ataupun polisi tidur yang dapat menyebabkan tingginya selisih nilai terbesar dan terkecil resultan akselerometer.

\section{E.Activity Daily Result}

Setelah melakukan pengujian sistem, maka data yang didapatkan diolah untuk mendapatkan nilai True Positive, False Negative, True Negative, dan False Positive yang berasal dari pengujian yang telah disesuaikan dengan skenario. Tabel 9 menunjukkan hasil dari activity daily result pada penelitian ini.

TABEL XI

ACTIVITY DAILY RESULT

\begin{tabular}{|l|l|l|l|l|l|l|}
\hline No & \multicolumn{1}{|c|}{ Skenario } & Total & \multicolumn{2}{|c|}{ Jatuh } & \multicolumn{2}{c|}{$\begin{array}{c}\text { Tidak } \\
\text { Jatuh }\end{array}$} \\
\cline { 4 - 7 } & & & TP & FN & TN & FP \\
\hline 1 & Jalan aspal rata & 60 & 28 & 2 & 26 & 4 \\
\hline 2 & $\begin{array}{l}\text { Jalanaspal } \\
\text { bergelombang }\end{array}$ & 60 & 29 & 1 & 27 & 3 \\
\hline 3 & $\begin{array}{l}\text { Jalan aspal } \\
\text { dengan } \\
\text { beberapa polisi } \\
\text { tidur }\end{array}$ & 60 & 30 & 0 & 20 & 10 \\
\hline & Total & 180 & 87 & 3 & 73 & 7 \\
\hline
\end{tabular}

Berdasarkan Tabel 11 maka didapatkan nilai sensitivity dan specitivity yang dihitung dengan sebagai berikut:

$$
\begin{aligned}
& \text { Sensitivity }=\frac{\mathrm{TP}}{T P+F N}=\frac{87}{90}=96 \% \\
& \text { Specitivity }=\frac{\mathrm{TN}}{T N+F P}=\frac{73}{90}=81 \%
\end{aligned}
$$

Sensitivity merupakan seberapa baik kemampuan sistem menganggap jatuh apabila kendaraan dalam kondisi benarbenar jatuh. Sedangkan specitivity merupakan seberapa baik kemampuan sistem menganggap tidak jatuh apabila kendaraan dalam kondisi tidak terjatuh. Dari hasil activity daily result di atas, nilai sensitivity yang diperoleh yaitu sebesar $96 \%$ dan nilai specitivity yang diperoleh yaitu sebesar 81\%, maka dari itu dapat disimpulkan bahwa kemampuan sistem mengganggap jatuh apabila kendaraan benar-benar dalam kondisi jatuh lebih tinggi dibandingkan kemampuan sistem menganggap tidak jatuh apabila kendaraan dalam kondisi tidak terjatuh.

\section{KESIMPULAN}

Berdasarkan hasil pengujian dan analisis sistem yang telah dilakukan, maka dapat disimpulkan bahwa :

Sensor akselerometer dan GPS Location yang terdapat pada smartphone dapat digunakan untuk mendeteksi kecelakaan lalu lintas. Hal ini dapat dibuktikan dengan tingginya sensitivity pada penelitian ini yaitu sebesar $96 \%$ dan akurasi sistem dalam mendeteksi kecelakaan pada ketiga kondisi jalanan aspal yang berbeda lebih dari 50\%.

\section{UCAPAN TERIMA KASIH}

Dalam menyelesaikan penelitian ini, penulis mengucapkan terima kasih kepada Bapak Kristian Adi 
Nugraha dan Bapak Laurentius Kuncoro Probo Saputra yang telah mengarahkan penelitian dengan baik. Juga diucapkan terima kasih kepada keluarga dan teman-teman seperjuangan program studi Informatika UKDW angkatan 2015 yang selalu setia mendukung dan mendoakan setiap saat.

\section{DAFTAR PUSTAKA}

[1] (n.d) Badan Pusat Statistika Indonesia. [Online]. Tersedia: https://www.bps.go.id/linkTableDinamis/view/id/1134

[2] Sylvia Merry, H. Duto Deddi, Saverina Tifanny. (2019). Perancangan Kampanye Sosial Peduli Korban Kecelakaan di Jalan. Jurnal DKV Adiwarna, Universitas Kristen Petra. [Online]. Tersedia: http://publication.petra.ac.id/index.php/dkv/article/view/8595

[3] N. Kurnia Lis., \& Gifary, Sharen. (2015). Intensitas Penggunaan Smartphone Terhadap Perilaku Komunikasi. Jurnal Sosioteknologi. [Online].Tersedia:

http://journals.itb.ac.id/index.php/sostek/article/view/1472/1045

[4] Riantana, R., H, B, C., \& Darsono. (n.d). Aplikasi Sensor Akselerometer pada Handphone Android Sebagai Pencatat Getaran Gempa Bumi Secara Online. Jurnal Fisika dan Aplikasinya vol 11.

[5] Ali, H., \& Z, Alwan. (April, 2015). Car Accident Detection Notification System Using Smartphone. International Journal of Computer Science and Mobile Computing. [Online]. Tersedia: https://www.researchgate.net/publication/291356742_Car_Accident Detection_and_Notification_System_Using_Smartphone.

[6] Tran. (2015). Optimization of an Accelerometer and GyrroscopeBased Fall Detection Algorithm. Journal of Sensors.

[7] Rakhman, A, Nugroho, L.E, Widyawan \& Kurnianingsih. (2014). Fall Detection System Using Accelerometer and Gyroscope Based on Smartphone. International Conference on Information Technology.

[8] Subekti, R., Bhaskoro, S. B, \& Melita. (2018). Pengendalian Kamera Berdasarkan Deteksi Posisi Manusia Bergerak Jatuh Berbasis Multi Sensor Akselerometer dan Gyroscope. ELKOMIKA.

[9] Jefiza, A. (2017). Sistem Pendeteksi Jatuh Berbasis Sensor Gyroscope dan Sensor Akselerometer Menggunakan Backpropagation. TESIS TEI142599.

[10] Kanedi, K. I., \& Ariyanti. (2015). Pemanfaatan Google Maps API pada Sistem Informasi Geografis Direktori Perguruan Tinggi di Kota Bengkulu. Jurnal Media Infotama.

[11] Nazruddin. S. (n.d) Menurut Safaat Nazruddin. [Online]. Tersedia: https://www.academia.edu/6916905/Menurut Safaat_Nazruddin?aut $\mathrm{o}=$ download

[12] Gunawan (2017) Accelerometer, Gyroscope, Proximity, Ambient Light, Digital Compass. [Online]. Tersedia: https://timur.ilearning.me/2018/03/09/pengertian-accelerometer.

[13] Suhardi, Triyanto, Dedi., \& Susetiyo, Fathan. (2016). Rancang Bangun Smart Vehicle untuk Mendeteksi Dini Kecelakaan dengan Pelaporan Visual pada Google Maps. Jurnal Coding, Sistem Komputer Untan.

[14] (2017). Bagaimana Cara Kerja Google Maps [Online]. Tersedia: http://komunitaskami.com/artikel/bagaimana-cara-kerja-googlemaps/.

[15] Setyawati, M. (n.d). Buku Pintar Fisika. (Edisi Pertama). 